\title{
ENSEÑANZA A DISTANCIA Y EDUCACIÓN A DISTANCIA: ¿DE QUÉ ESTAMOS HABLANDO?
}

\author{
Dr. Enrique Lorenzo*
}

\section{Introducción}

El propósito del presente artículo es discutir y analizar los usos y significados que las frases "educación a distancia" y "enseñanza a distancia" tienen en el discurso pedagógico contemporáneo. Partimos del supuesto que con frecuencia estas frases se utilizan como equivalentes, permitiendo esto la fusión de objetos de estudio distintos. En el ámbito de la educación presencial, desde hace varios siglos, se han señalado las diferencias entre "educación" y "enseñanza" y esto ha permitido el desarrollo de referentes teóricos que facilitan el estudio y análisis de situaciones prácticas. La fusión, o confusión, que se manifiesta en el terreno de la educación no presencial, parece ser un tema poco relevante a juzgar por la escasa reflexión que hay sobre este tópico. No obstante, pensamos que es buen momento para iniciar ese proceso de construcción. Es por eso que hoy acercamos estas breves reflexiones sobre el tema en cuestión.

\section{Los modelos didácticos en Educación a Distancia}

Según Fainholc (1999), en opinión que compartimos, la índole compleja de los contextos en donde se inscriben los programas y proyectos de Educación a Distancia en la contemporaneidad, obliga a revisar sus supuestos filosóficos y su concepción pedagógica-tecnológica en el marco del tránsito de paradigmas. Resulta necesario en este momento tomar una postura con referencia a qué entendemos por Educación a Distancia.

Si bien la frase Educación a Distancia remite a diferentes significados y sentidos, entendemos apropiado en este trabajo adoptar como referente la conceptualización desarrollada por Holmberg (citado por García Aretio, 1994) al señalar que "El término de 'educación a distancia' cubre las distintas formas de estudio a todos los niveles que no se encuentren bajo la continua, inmediata supervisión de los tutores presentes con sus estudiantes en el aula, pero que sin embargo, se benefician de la planificación, guía y seguimiento de una organización tutorial" (1994:34).

Esta pluralidad de significados para referirse a la Educación a Distancia parece trasladarse también en la distinción "educación/enseñanza a distancia". Al respecto, y tratando este tema, García Aretio nos dice que en el momento de definir educación (o enseñanza) a distancia no se ha reparado en la diferenciación de estos campos disciplinares ( Pedagogía y Didáctica). Para ejemplificar esta falta de rigor terminológico y epistemológico el autor español comenta: "No entramos a matizar las importantes diferencias entre estos dos conceptos. La razón es la de que en el estudio comparado de autores, al que posteriormente hacemos referencia, éstos han sido utilizados indistintamente" (1994: 27).

Podríamos comenzar a formular algunas hipótesis sobre esta neutralización semántica. Si bien es cierto que en la historia de las ciencias de la educación este tema ha sido constantemente señalado, hoy día podemos decir que la investigación en el área ha permitido establecer diferencias básicas entre educación y enseñanza. El primero de los términos se lo vincula fuertemente con el campo pedagógico, mientras que el segundo es objeto de estudio de la Didáctica (Camilloni, 1995; Litwin, 1997). 
Otra hipótesis que podría explicar esa neutralización semántica podría estar dada por la escasa y débil reflexión teórica operada en el terreno de la Educación a Distancia. Al respecto, nuevamente García Aretio nos dice que "las bases teóricas de la educación a distancia son efectivamente frágiles, pero la verdad es que no resulta fácil elaborar teorías en este campo" (1994: 65).

No obstante, en el rastreo bibliográfico realizado para la elaboración de este artículo, hemos encontrado algunas líneas orientadoras, que más allá de favorecer la confusión semántica, cooperan con la construcción de la teoría. En propio García Aretio anota que "La teoría de la educación a distancia de Holmerg como método de conversación didáctica guiada implica que el carácter de la buena educación a distancia es asumir el estilo de una buena conversación guiada, orientada hacia el aprendizaje" (1994:72). Esta idea vinculada con la comunicabilidad didáctica puede ser entendida, y en esa perspectiva la incorporamos, como una reflexión intencional sobre los problemas didácticos. De alguna manera, también en la Educación a Distancia se ha estado, y se está, pensando en la presentación de los contenidos, en los criterios de selección y jerarquización de los saberes, en las formas más apropiadas para generar ambientes de aprendizajes, en las interacciones entre sujetos y objetos de conocimiento. Si bien es cierto que estas apreciaciones sobre los rasgos o características de los modelos didácticos en Educación a Distancia están en pañales y solicitan un tratamiento más riguroso, desde la perspectiva epistemológica fundamentalmente, no podemos desconocerlos en el momento de pensar en la enseñanza a distancia.

García Aretio comenta al respecto: "La enseñanza a distancia por su propia estructura y objetivos, brinda un ámbito de aprendizaje donde el adulto puede aprender aquello que personalmente le interese y responda a sus propias necesidades, desarrollando una vida que le resulte más satisfactoria y llena de sentido (Pérez Serrano, 1986: 3-7)" (1994:164). Este autor nos está ofreciendo algunas referencias para "pensar" modelos de intervención didáctica, si bien éstos no están explicitados.

En otro de sus trabajos, García Aretio (1998) nos proporciona sugerencias sobre cómo estructurar una unidad y guía didáctica. En esta comunicación, el autor analiza y comenta formas de organizar y dar secuencia a los contenidos tanto de enseñanza como de aprendizaje. Las sugerencias refieren tanto a contenido como a aspectos lingüísticos, así, en un momento dice " Repeticiones, analogías, ejemplos y comparaciones ayudan a presentar las mismas ideas de forma diferente, ello siempre atendiendo a la preparación y experiencias previas del lector que podría rechazar el texto por monótono" (1998:175). La reiterada insistencia en contemplar al destinatario del texto, solicitando la adecuación del discurso didáctico para generar genuinos y significativos ambientes de aprendizaje, puede interpretarse como un rasgo de la propuesta didáctica en Educación a Distancia.

De la lectura de estas citas podemos inferir que en el ámbito de la Educación a Distancia hay gran preocupación por definir procesos de enseñanza que favorezcan procesos de aprendizaje. Parecería que el término "educación" aparece, con frecuencia, como sustituto y equivalente a "enseñanza" o tal vez se intenta reducir la mayoría de los problemas y temas educativos al terreno de la enseñanza. Se trate de un caso u otro, lo cierto es que debemos contribuir con nuestros estudios e investigaciones a diferenciar y clarificar los distintos campos de estudio de cada disciplina: Educación a Distancia y Enseñanza a Distancia. El acercamiento, además, de la Enseñanza a Distancia a temas instrumentales y normativos/ prescriptivos impide un nivel de reflexión epistemológica. Es necesario desprenderse de esa mirada tecnicista para poder desarrollar una auténtica teoría de la enseñanza: en nuestro caso, una auténtica teoría sobre "los procesos de enseñanza en contextos no presenciales".

\section{El problema planteado}

El hecho de que no estén explicitados estos modelos didácticos y que aún persista en este terreno una confusión entre educación y enseñanza a distancia, nos ha motivado para pensar preguntas de investigación en el área que puedan aportar algunos elementos teórico-prácticos que favorezcan la consolidación de una Didáctica en la Educación a Distancia. Nos parece que con los elementos que hoy

8 - Universidad ORT Uruguay 
tenemos no estamos en condiciones de formular propuestas adecuadas para diseñar modelos de intervención docente, ni siquiera para elaborar una síntesis sobre el estado del arte. Esta búsqueda bibliográfica y posterior reflexión nos ha llevado a identificar un problema: la confusión entre educación a distancia y enseñanza a distancia. Derivados de éste, se generan una serie de preguntas:

¿cómo repercute esta falta de diferenciación conceptual (educación/enseñanza) en dichos modelos?

¿cómo se manifiesta la transposición didáctica en la Educación a Distancia?

¿cuáles son las configuraciones didácticas más frecuentes en las propuestas de enseñanza en esta modalidad?

¿qué características presenta la evaluación de las formas de intervención didáctica?

Naturalmente que estas no son todas las preguntas que se podrían definir, ni todas ellas puedan ser estudiadas en forma simultánea. En función de las necesidades e intereses de cada institución que desarrolla propuestas de Educación a Distancia, se seleccionarán aquellas preguntas que sean más urgentes para mejorar la calidad de dicha educación. Gestar, impulsar y desarrollar trabajos de investigación en esta línea, creemos que puede contribuir sensiblemente con la conformación de un referente teórico, necesario y hoy casi ausente, en la Educación y en la Enseñanza a Distancia.

\section{Bibliografía}

Busto, J.; Osoco, A. 1990 "La renovación pedagógica del profesorado" en Cuadernos de Pedagogía $\mathrm{N}^{\mathrm{o}} 183$, páginas 66-69.

Cabrero, D.; Martín, P.; Simón, C. 1994 "Formación permanente del profesorado en la modalidad a distancia y basada en soportes temáticos. Estudio de un caso" en revista Educación a Distancia No 9, páginas 31-39.

Camilloni, A y otras 1995 Corrientes didácticas contemporáneas. Bs. As.: Aique.

Chevallard, Y 1997 La transposición didáctica. Bs. As.: Aique.

Cirigliano, G. 1983 La educación abierta. Bs. As.: El Ateneo.

Davini, M. C. 1995 La formación docente en cuestión: política y pedagogía. Bs. As.: Paidós.

De Alba, A. 1990 Teoría y educación. en torno al carácter científico de la educación. México: UNAM

Díaz Barriga, A. 1991 Didáctica. Aportes para una polémica. Bs. As.: Aique.

Díaz Barriga, A. 1997 Tarea docente. Bs. As.: Aique.

Fainholc, B. 1990 La tecnología educativa propia y apropiada. Bs. As.: Humanitas.

Fainholc, B. 1997 Nuevas tecnologías de la información y la comunicación. Bs. As.: Aique.

Fainholc, B. 1999 La interactividad en la educación a distancia. Bs.As.: Paidós.

García Aretio, L. 1994 Educación a distancia hoy. Universidad Nacional de Educación a Distancia. Madrid. 
García Aretio, L. (ed.) 1998 El material impreso en la enseñanza a distancia. Universidad Nacional de Educación a Distancia: Madrid.

Litwin, E. 1996 Tecnología educativa. Bs.As.: Paidós.

Litwin, E. 1997 Las configuraciones didácticas. Bs.As.: Paidós.

Pansza, M. y otros 1992 Fundamentación de la didáctica. México: Guernika.

Pansza, M. y otros 1993 Operatividad de la didáctica. México: Guernika.

* Secretario Docente, Instituto de Educación, Universidad ORT Uruguay. 